with the risks of MSDs of different bodily sites in general employees of Taiwan.

Methods Participants were representative employees aged 2565 years from a nationwide survey of 2016. Self-administered questionnaires were used to obtain information concerning work-related ergonomic and psychosocial factors, employment conditions, and MSDs of different bodily sites over the past 12 months.

Results A total of 5242 male and 4164 female employees was included. Workers who were older, with lower education levels, being manual skilled or low skilled workers, worked in the construction industry, and being employed in small-sized enterprises had higher risks for MSDs, and the most common bodily site were the neck/shoulders, low back, and wrists/ hands. Psychological demands, workplace justice and ergonomic factors were significantly associated with MSDs. Furthermore, results of separate regression models performed for MSDs of different bodily sites showed that higher psychological demands and lower workplace justice were associated with MSDs of the neck/shoulders to a greater extent than other work-related factors, while whole-body-related ergonomic factors and hand-related ergonomic factors were more greatly associated with MSDs of lower back and wrists/hands, respectively.

Conclusions MSDs were more prevalent in workers with lower socioeconomic positions. Differential contribution of specific types of work-related ergonomic and psychosocial factors to the risks of specific types of MSDs should be taken into consideration in the management of MSDs in the workplace.

\section{P.3.18 ASSOCIATION BETWEEN NIGHTSHIFT SCHEDULE AND MENTAL HEALTH SYMPTOMS AMONG FACTORY WORKERS: A CROSS-SECTIONAL STUDY}

Sophia Francesca Lu*. Carrs-Q, Queensland University Of Technology, Brisbane, Australia

\subsection{6/OEM-2019-EPI.277}

Introduction Nightshift is one of the major issues in worktime schedule. The association between working at night and the occurrence of mental health symptoms has been a subject of considerable debate. This study aimed to look at the association between working at night and mental health symptoms, and mediating factors to this association.

Methods This study looked at a database of 500 factory workers that originally investigated hazard exposures and occupational health of workers in export processing zones in the Philippines. Associations between shift schedule and probable confounders with frequency of occurrence of mental health symptoms were studied using chi-square test of association. Multiple logistic regression was used to analyze the overall association.

Results The study showed that work schedule, work load and occurrence of mental health symptoms are associated with night schedule. The crude odds ratio for the association between shift schedule and frequency of occurrence of mental health symptoms is $2.13(0.77-5.81)$. This means that without adjusting for confounders, those who work in the evening are 2.13 times more likely to have frequent occurrence of mental health symptoms as compared to those who work in the morning. Specifically, among females, those who work at night are 2.97 times more likely to have frequent occurrences of mental health symptoms compared to those who work in the morning.
Controlling for age, sex, educational attainment, tenure, work load, and exposure to occupational hazards, those who are working at night are $2.13(0.79-5.71)$ times more likely to have frequent episodes of mental health symptoms compared to those who work in the morning. Those who are frequently exposed to occupational hazards are 5.78 (1.17-28.71) times more likely to have frequent mental health symptoms.

Conclusion The study has shown that among Filipino factory workers, nightshift work is associated with mental health symptoms.

\section{P.3.19 EFFECT OF OCCUPATIONAL WORK AND SAFETY ISSUES ON ROAD CRASH INJURIES IN THE PHILIPPINES}

Sophia Francesca Lu*. Carrs-Q, Queensland University Of Technology, Brisbane, Australia

\subsection{6/OEM-2019-EPI.278}

Background This study looked at occupational road crashes and work schedule among truck and bus drivers in comparison to other drivers and motorists on the road of Metro manila which is one of the cities globally with a high traffic density. One of the most precarious work occupations is driving especially buses used for public transportation, and trucks for commercial activities. This is most astute in the metrolopolis.

Methods The study used meta-analysis of previous studies conducted, grey literature, government statistics, and validation through key database research in concerned national government agencies involved in road traffic from 2010-2015.

Results The study found that the in terms of the number of public utility vehicles registered in Metro Manila (2015), $51.27 \%$ were buses and $20.21 \%$ were trucks. Majority of the drivers worked more than 12 hours a day. In terms of time and peak of accidents, it is alarming to note that about $35 \%$ of the road crashes occurred from 22-23 gmt (2010-2015), and $30 \%$ from 23-24 (2010-2015) gmt. Human error accounted for the overwhelming cause of road crashes such as drunk driving, beating the red light, sleepiness, accounting for $99.52 \%$ in $2012,99.47 \%$ in $2013,95.33 \%$ in 2014 , and $97.19 \%$ in 2015. Majority of the drivers worked over prolonged hours on the road that may cause fatigue and sleepiness which are the highest risk factor to road accident based on the study.

Conclusion The study has shown how risky driving is as an occupation especially due to the work schedule and work issues. The study suggests developing better information, education and communication campaign as well as policies particularly on work conditions favorable to bus and truck drivers, and likewise, considering work schedule in road safety among drivers which composes one of the risky occupations.

\section{P.3.20 HOSPITALIZATION OUTCOMES OF ROAD TRAFFIC INJURY PATIENTS IN THE LARGEST HOSPITAL IN THE PHILIPPINES}

Sophia Francesca Lu*. Carrs-Q, Queensland University Of Technology, Brisbane, Australia

\subsection{6/OEM-2019-EPI.279}

Background Road traffic injuries claim are among the leading causes of preventable death, claiming around 7000 lives every year. Accordingly, injuries to the head and neck are the main causes of death and disability. 